\title{
Application of the PM6 semi-empirical method to modeling proteins enhances docking accuracy of AutoDock Zsolt Bikadi and Eszter Hazai*
}

\author{
Address: Virtua Drug Ltd, Csalogany Street 4C Budapest, Hungary \\ Email: Zsolt Bikadi - zsolt.bikadi@virtuadrug.com; Eszter Hazai* - eszter.hazai@virtuadrug.com \\ * Corresponding author
}

Published: II September 2009

Journal of Cheminformatics 2009, I:15 doi:10.1186/1758-2946-I-15

This article is available from: http://www.jcheminf.com/content/I/I/I5

(c) 2009 Bikadi and Hazai; licensee BioMed Central Ltd.

This is an Open Access article distributed under the terms of the Creative Commons Attribution License (http://creativecommons.org/licenses/by/2.0), which permits unrestricted use, distribution, and reproduction in any medium, provided the original work is properly cited.
Received: 23 June 2009

Accepted: II September 2009

\begin{abstract}
Background: Molecular docking methods are commonly used for predicting binding modes and energies of ligands to proteins. For accurate complex geometry and binding energy estimation, an appropriate method for calculating partial charges is essential. AutoDockTools software, the interface for preparing input files for one of the most widely used docking programs AutoDock 4, utilizes the Gasteiger partial charge calculation method for both protein and ligand charge calculation. However, it has already been shown that more accurate partial charge calculation - and as a consequence, more accurate docking- can be achieved by using quantum chemical methods. For docking calculations quantum chemical partial charge calculation as a routine was only used for ligands so far. The newly developed Mozyme function of MOPAC2009 allows fast partial charge calculation of proteins by quantum mechanical semi-empirical methods. Thus, in the current study, the effect of semi-empirical quantum-mechanical partial charge calculation on docking accuracy could be investigated.
\end{abstract}

Results: The docking accuracy of AutoDock 4 using the original AutoDock scoring function was investigated on a set of 53 protein ligand complexes using Gasteiger and PM6 partial charge calculation methods. This has enabled us to compare the effect of the partial charge calculation method on docking accuracy utilizing AutoDock 4 software. Our results showed that the docking accuracy in regard to complex geometry (docking result defined as accurate when the RMSD of the first rank docking result complex is within $2 \AA$ of the experimentally determined X-ray structure) significantly increased when partial charges of the ligands and proteins were calculated with the semi-empirical PM6 method.

Out of the 53 complexes analyzed in the course of our study, the geometry of 42 complexes were accurately calculated using PM6 partial charges, while the use of Gasteiger charges resulted in only 28 accurate geometries. The binding affinity estimation was not influenced by the partial charge calculation method - for more accurate binding affinity prediction development of a new scoring function for AutoDock is needed.

Conclusion: Our results demonstrate that the accuracy of determination of complex geometry using AutoDock 4 for docking calculation greatly increases with the use of quantum chemical partial charge calculation on both the ligands and proteins. 


\section{Background}

The role of in silico chemistry is emerging in drug design and discovery. In an effort to find lead compounds at lower cost and greater speed, computational chemistry methods have focused on developing fast and highly efficient molecular docking methods for virtual screening $[1,2]$. In recent years, progress has been made in developing docking algorithms that predict ligand binding to proteins and by now several docking programs are available such as AutoDock, $[3,4]$, GOLD, [5,6], Glide, $[7,8]$ and FlexX $[9,10]$. Among these, the AutoDock program was the most popular according to a recent study [11].

Molecular docking methods include the search in space for the energetically most favorable conformation of a protein-ligand complex and the scoring of the resulting geometries with respect to binding energy $[1,12]$. The production of the right docking pose and the scoring of the complex geometries are often treated as two separate problems. It should be noted however, that many docking programs use the scoring function in the process of finding the complex with lowest energy [13]; thus, scoring and geometry prediction should rather be treated as one problem and it can be assumed that minimizing the RMSD between predicted and experimentally determined complex geometries would lead to more accurate prediction of binding free energies at the same time.

In AutoDock 4 energy scoring function the calculation of pair-wise atomic terms includes evaluations for different secondary interactions, dispersion/repulsion, hydrogen bonding, electrostatics, and desolvation [14]. Thus, calculation of accurate partial charges on the ligand and the protein is expected to have a profound effect on both the docking conformation and on the energy score of the resulting complex, possibly leading to more accurate estimation of complex geometry and binding energy. There are several charge calculation methods which lead to significant differences in the partial charges assigned to the different atoms [15]. AutoDockTools program enables the user to use empirical charge calculations, Gasteiger or Kollman united charges. However, this charge calculation method has been shown to yield less accurate partial charges than semi-empirical methods [16]. Additionally, Gasteiger charge calculation [17] does not handle electrons, presenting a major flaw in the docking calculation of metalloproteins.

Moreover, in a recent study analyzing the effect of various charge models in docking results it was concluded that the quantum mechanical charge calculation method yielded significantly better docking results $[15,18]$, both in terms of binding geometry and energy. It should be noted that in these studies only the ligand charges were calculated with the quantum mechanical method, while the protein charges were calculated with the Gasteiger-Hückel method. Still, semi-empirical charge calculation on the ligand was enough to yield more accurate docking results. Quantum mechanical polarization of the ligand also has been shown to greatly improve docking accuracy [19]. Illingworth and his colleagues [20] extended this method by calculating polarization not only on the ligands, but also on the target macromolecules using Amber charges [21]. However, those implementations involve the knowledge of the structure of the complex and iteration of quantum mechanical calculations and thus cannot be treated as a practical tool in docking [20]. Raha and Merz used semiempirical QM based scoring function for predicting binding energy and binding mode of a diverse set of proteinligand complexes [22]. The authors used a scoring function designed using semi-empirical QM Hamiltonians to discriminate between native and decoy poses generated from the program AutoDock 4. Recently, a newly developed semi-empirical PM6 method was introduced that corrects major errors in AM1 and PM3 calculations and is useful for semi-empirical charge calculations of small ligands as well as proteins [23]. Besides that, all main group elements and transition metals are parameterized in PM6 in MOPAC2009 software. Thus, using the PM6 method for assigning partial charges to both the ligand and the protein would have two main advantages i.e. docking of metalloproteins can accurately be handled and semiempirical charge calculation is expected to yield more accurate docking results in general.

In the current study it was analyzed whether PM6 semiempirical charge calculation on both the ligands and their host proteins increases docking accuracy in terms of complex geometry and binding energy using AutoDock 4 software. To the author's knowledge this is the first study where MOPAC2009 software is used for semi-empirical charge calculations on proteins systematically for preparing input files for docking calculations. 53 protein-ligand complexes were analyzed for which both crystallographic structure determination and binding data were available. The partial charges of the ligands and proteins were calculated using 1.) Gasteiger 2.) PM6 charge calculation methods and the ligands were docked using AutoDock 4 software back into their host proteins. The resulting complex geometries were analyzed for their RMSD as compared to the available X-ray structure and their binding energies as calculated by the AutoDock 4 scoring function (docking result defined as accurate when the RMSD of the first rank docking result complex is within $2 \AA$ of the experimentally determined X-ray structure). Our results indicated that the use of the PM6 semi-empirical charge calculation method for assigning partial charges to both the protein and the ligand atoms greatly increases docking accuracy as compared to the Gasteiger charge calculation 
method (available in AutoDockTools) in terms of complex geometry.

\section{Results}

In Table 1 structural and experimental data of the investigated protein-ligand complexes are summarized. The 53 complexes used in this study were all characterized by a resolution below $3.2 \AA$. The complexes were chosen partly from the AutoDock 3.0 calibration set [68], from a recently published paper examining different docking software [13] and from the core set of PDBbind Database [69]. The chosen structures possess structurally diverse ligands in complex with a heterogeneous collection of proteins (see Table 1). It should be noted that for some structures with lower resolution (although chosen from the AutoDock 3.0 calibration set), an RMSD-based comparison of docked versus experimental structure might not always lead to a meaningful result as partial occupancies might occur that are not reflected by a single ligand structure. Using this dataset, ligand and protein structures were setup using two different methods, (i), calculating Gasteiger charges on both the ligands and the proteins using AutoDockTools and (ii), calculating PM6 charges on both the ligands and the proteins using MOPAC2009 [70] on Docking Server (see Method section for details). Docking calculations were performed twice on the dataset (in case of both ligand and protein set up methods) and the results were then compared to the experimentally determined complex structures.

\section{Estimation of binding energies}

Figure 1 shows the correlation between experimentally determined and predicted binding energies as calculated by AutoDock 4 . The correlation between the predicted and observed binding energy is rather limited (correlation coefficient is about 0.51). In most cases the binding energy is underestimated by the prediction. It should be noted that the correlation coefficient increases by considering only the hits where the first rank result yielded an RMSD within $2 \AA$ of the X-ray structure (correlation coefficient is about 0.60) in cases where Gasteiger partial charge calculation method is used. Thus, it can be concluded that good geometry prediction does contribute to accurate binding energy estimation. Compared to Gasteiger, PM6 had somewhat lower regression constant $(\mathrm{R}=0.41$ for all cases, $\mathrm{R}=0.46$ with an RMSD below $2 \AA)$ in the docking studies (Figure 1). Thus, the change in the method of partial charge calculation even decreased the predicted total binding energy using the current AutoDock 4 scoring function. This result is not surprising considering the fact that AutoDock 4 scoring function was optimized using the Gasteiger charge calculation method.

\section{Geometry prediction in docking studies using Gasteiger charges on both ligand and protein atoms}

The results of the docking calculations using Gasteiger charges on both the ligand and the protein are summarized in Table 2. Analyzing the first rank results, 28 of the 53 complexes resulted in an accurate docking result (lowest RMSD within $2 \AA$ as compared to the X-ray structures). Considering the most populated cluster (and not the lowest energy) as a first rank result, 30 of the 53 dockings were able to successfully predict the experimentally observed binding mode. Among these successful predictions, 24 were found to be the lowest energy and most populated result at the same time. Docking calculations using Gasteiger charges resulted in 14 "dominant" (more than $60 \%$ of the dockings in the same cluster) first rank results in successful predictions. In 8 cases there were no accurate dockings (RMSD below $2.0 \AA$ in any of the clusters) among the docking runs. The average RMSD of the first rank results was $2.34 \AA$ ( $1.83 \AA$ without outliers).

\section{Geometry prediction in docking studies using PM6 charges on both ligand and protein atoms}

Docking calculations were performed for the same dataset, using the PM6 method for both protein and ligand setup [23]. Comparing partial charges on a selected atom, PM6 method gives higher absolute value for partial charges than the Gasteiger calculation. In the case of proteins, the absolute value of partial charges returned a value of about 1.6 times greater on average than in the case of Gasteiger charge calculation. i.e. the sum of the absolute value of partial charges was 628.8 in case of Gasteiger charge calculation, while it was 1014.2 using PM6 in case of the protein with PDB entry 4HMG; the sum of absolute values of partial charges was 354.1 with Gasteiger charge calculation and it increased to 570.8 with PM6 partial charge calculation in case of the protein with PDB code 1HVR. The ratio of absolute partial charge values using Gasteiger and PM6 calculation methods was found to be constant among the investigated proteins; Gasteiger/PM6 $0.619 \pm 0.020$ (data not shown). In the AutoDock 4 scoring function, the sum of absolute partial charges effects the solvation parameter, which is calculated using the absolute value of partial charge for a given atom:

$$
S_{i}=\left(A S P_{i}+Q A S P \times\left|q_{i}\right|\right)
$$

In the above equation (Scheme 1) ASP and QASP are the atomic solvation parameters. The ASP was calibrated using six atom types; while a single QASP is calibrated over the set of charges on all atom types. Since the partial charges calculated with Gasteiger method are 0.619 times lower than the ones calculated with PM6, the QASP parameter in AutoDock 4 and Autogrid source code was reduced by 0.619 . Thus, the final QASP parameter used in our AutoDock 4 calculation was 0.00679 (instead of 
Table I: Experimental data for the 54 protein-ligand complexes.

\begin{tabular}{|c|c|c|c|c|}
\hline PDB code & Protein & $\operatorname{Res}(\AA ̊)$ & Ligand & Structure Ref. \\
\hline$\underline{\mathrm{IAI} 5}$ & Penicillin acylase & 2.4 & m-nitrophenylacetic acid & {$[24]$} \\
\hline$\underline{I A J P}$ & Penicillin acylase & 2.3 & 2,5-dihydroxyphenylacetic acid & {$[24]$} \\
\hline$\underline{\text { IAMW }}$ & Heat shock protein 90 & 1.9 & ADP & {$[25]$} \\
\hline IBGQ & Heat shock protein 90 & 2.5 & radicicol & {$[26]$} \\
\hline$\underline{I C B R}$ & Retionic acid binding protein & 2.9 & retinoic acid & [27] \\
\hline$\underline{\text { ID3Q }}$ & Human thrombin & 2.9 & benzo $[b]$ thiophene derivative & {$[28]$} \\
\hline$\underline{\text { ID3T }}$ & Human thrombin & 3.0 & benzo [b]thiophene derivative & {$[28]$} \\
\hline$\underline{\text { IDWB }}$ & a-Thrombin & 3.2 & benzamidine & [29] \\
\hline$\underline{\text { IFLR }}$ & Immunoglobulin & 1.9 & fluorescein & [30] \\
\hline$\underline{I G N I}$ & Human serum albumin & 2.4 & oleic acid & {$[31]$} \\
\hline$\underline{\text { IHV] }}$ & HIV-I Protease & 2.0 & A7879I & [32] \\
\hline$\underline{\text { IHVR }}$ & HIV-I Protease & 1.8 & XK263 & [33] \\
\hline$\underline{\mathrm{IK}} 4 \mathrm{G}$ & tRNA-guanine transglycosylase & 1.7 & quinazoline derivative & [34] \\
\hline$\underline{|K V|}$ & p38 MAP kinase & 2.5 & pyrazol derivative & {$[35]$} \\
\hline$\underline{\text { ILIF }}$ & Adipocyte lipid-binding protein & 1.6 & stearic acid & [36] \\
\hline$\underline{\mathrm{MON}}$ & Dialkylglycine decarboxylase & 2.2 & I-aminocyclo-pentanephosphonate & [37] \\
\hline$\underline{\mathrm{MOQ}}$ & Dialkylglycine decarboxylase & 2.0 & S-I-amino-ethanephosphonate & [37] \\
\hline$\underline{\text { IOLU }}$ & $\begin{array}{l}\text { Branched-chain alpha-ketoacid } \\
\text { dehydrogenase kinase }\end{array}$ & 1.9 & thiamin diphosphate & [38] \\
\hline$\underline{108 T}$ & cAMP-dependent protein kinase & 2.0 & $\begin{array}{c}\text { (R)-trans-4-(I-aminoethyl)-n-(4-pyridyl) } \\
\text { cyclohexanecarboxamide }\end{array}$ & [39] \\
\hline$\underline{I R B P}$ & Retinol-binding protein & 2.0 & retinol & {$[40]$} \\
\hline 1539 & tRNA-guanine transglycosylase & 2.0 & 2-aminoquinazolin-4(3H)-one & {$[4 I]$} \\
\hline$\underline{1 U 33}$ & Alpha-amylase & 2.0 & 5-trihydroxy-6-hydroxymethyl-piperidin-2-one & [42] \\
\hline$\underline{\text { IULB }}$ & Purine nucleoside phosphorylase & 2.8 & guanine & {$[43]$} \\
\hline IUWT & Beta-glycosidase & 2.0 & D-galactohydroximo-1,5-lactam & {$[44]$} \\
\hline$\underline{I X 8 R}$ & $\begin{array}{l}\text { 3-Phosphoshikimate I- } \\
\text { carboxyvinyltransferase }\end{array}$ & 1.5 & phosphonate analogue & [45] \\
\hline$\underline{|X D|}$ & Alpha-amylase & 2.2 & acarbose derived hexasaccharide & {$[46]$} \\
\hline
\end{tabular}


Table I: Experimental data for the 54 protein-ligand complexes. (Continued)

\begin{tabular}{|c|c|c|c|c|}
\hline$\underline{\text { IYDT }}$ & cAMP-dependent protein kinase & 2.3 & $\begin{array}{l}\mathrm{n}-[2-(4-\text { bromocinnamylamino)ethyl]-5- } \\
\text { isoquinoline }\end{array}$ & [47] \\
\hline$\underline{\text { ZC9 }}$ & Dialkylglycine decarboxylase & 2.0 & pyridoxamine 5-phosphate & {$[48]$} \\
\hline$\underline{2 A C K}$ & Acetylcholinesterase & 2.4 & edrophonium ion & [49] \\
\hline$\underline{2 B A J}$ & p38alpha Map kinase & 2.3 & pyrazol derivative & {$[50]$} \\
\hline$\underline{2 B A K}$ & p38alpha Map kinase & 2.2 & nicotinamid derivative & {$[50]$} \\
\hline$\underline{2 \text { CEQ }}$ & Beta-glycosidase & 2.1 & glucoimidazole & {$[51]$} \\
\hline$\underline{2 C E T}$ & Beta-glycosidase & 2.0 & phenethyl-substituted glucoimidazole & [51] \\
\hline$\underline{2 C G R}$ & Immunoglobulin & 2.2 & $\mathrm{~N}$-trisubstituted guanidine & [52] \\
\hline$\underline{2 \mathrm{CPP}}$ & Cytochrome P-450cam & 1.6 & camphor & [53] \\
\hline$\underline{2 \mathrm{D} 3 \mathrm{U}}$ & RNA-dependent RNA polymerase & 2.0 & non-nucleoside analogue inhibitor I & [54] \\
\hline$\underline{2 D} 3 Z$ & RNA-dependent RNA polymerase & 1.8 & non-nucleoside analogue inhibitor II & [54] \\
\hline$\underline{2 F D P}$ & Beta-secretase & 2.5 & amino-ethylene inhibitor & {$[55]$} \\
\hline$\underline{2 G 94}$ & Beta-secretase & 1.9 & valinamide derivative & [56] \\
\hline$\underline{2 G B P}$ & D-galactose/D-glucose binding protein & 1.9 & glucose & [57] \\
\hline$\underline{2 I F B}$ & Fatty-acid-binding protein & 2.0 & palmitic acid & {$[58]$} \\
\hline$\underline{21 W X}$ & Heat shock protein 82 & 1.5 & synthetic macrolactone & [59] \\
\hline$\underline{2}] 77$ & Beta-glycosidase & 2.1 & deoxynojirimycin & [Gloster, to be published] \\
\hline 2]78 & Beta-glycosidase & 1.7 & gluco-hydroximolactam & [Gloster, to be published] \\
\hline$\underline{2 Q F U}$ & $\begin{array}{l}\text { 3-Phosphoshikimate I- } \\
\text { carboxyvinyltransferase }\end{array}$ & 1.6 & shikimate-3-phosphate & [60] \\
\hline$\underline{2 Q W B}$ & Neuraminidase & 2.0 & sialic acid & [61] \\
\hline 2QWD & Neuraminidase & 2.0 & 4-amino-Neu5Ac2en & [6I] \\
\hline$\underline{2 R 04}$ & Rhinovirus I4 coat protein & 3.0 & W7I, antiviral agent & {$[62]$} \\
\hline$\underline{2 X I S}$ & Xylose isomerase & 1.6 & D-xylitol & [63] \\
\hline$\underline{2 Y P I}$ & Triose phosphate isomerase & 2.5 & 2-phosphoglycolic acid & [64] \\
\hline$\underline{3 P T B}$ & b-Trypsin & 1.8 & benzamidine & [65] \\
\hline$\underline{4 H M G}$ & Hemagglutinin & 3.0 & sialic acid & [66] \\
\hline$\underline{7 A B P}$ & Arabinose-binding protein & 1.7 & fucose & [67] \\
\hline
\end{tabular}




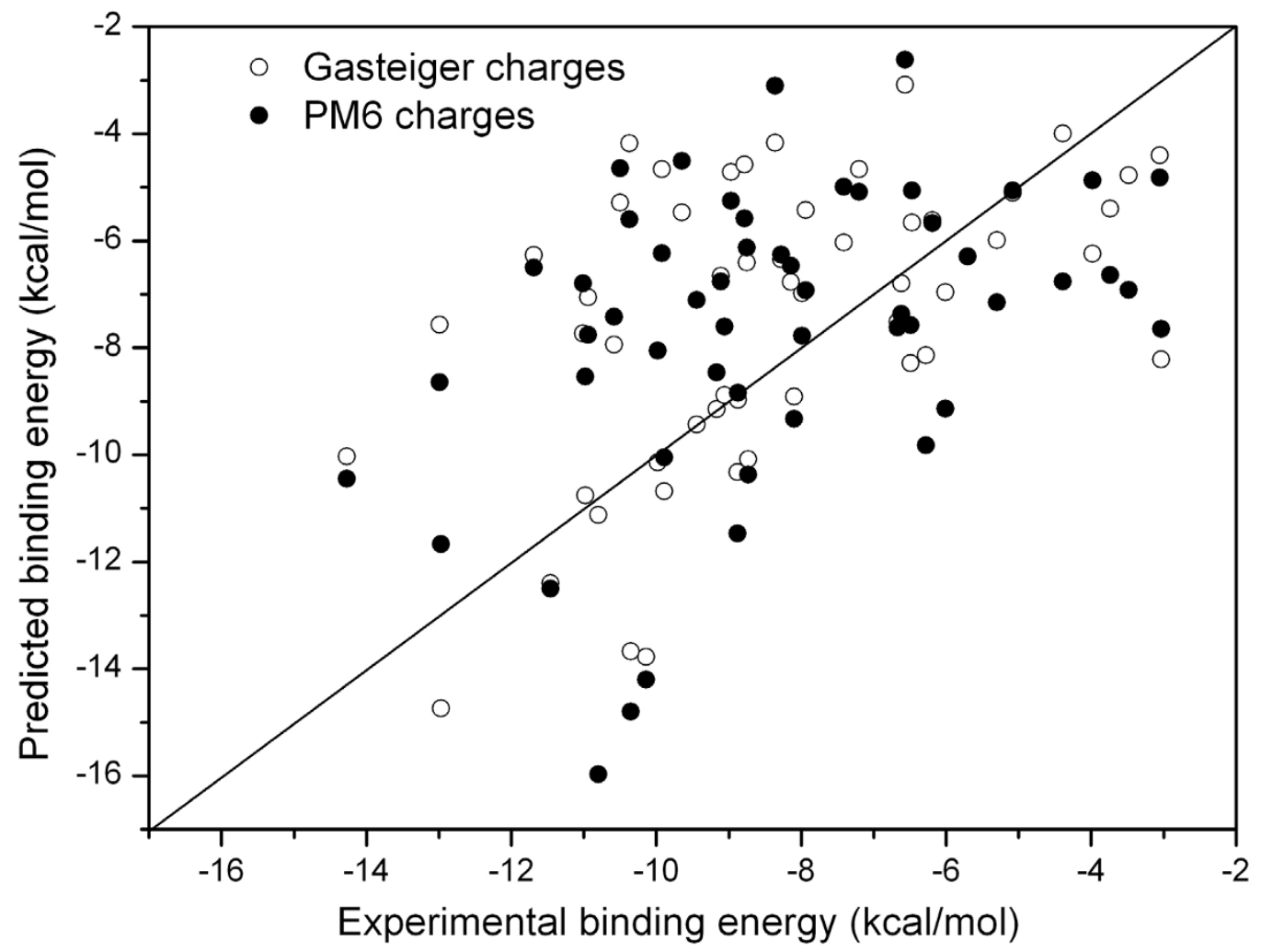

Figure I

Correlation between experimental and predicted binding energies using Gasteiger and PM6 charge calculations.

0.01097) when the PM6 method was used for partial charge calculation.

In Table 3 the results of docking calculations with the new QASP parameter and using PM6 charges on both the ligand and the protein can be seen. 38 out of 53 docking calculations resulted in best energy-lowest RMSD as compared to X-ray. Considering the most populated clusters (and not the lowest energy), 42 first rank and 9 second rank results were observed. In 36 of the 42 successful dockings, the first rank results were "dominant" (at least $60 \%$ of the runs resulted in the same cluster) in the docking calculations. In all cases, where the most populated cluster's frequency was above 50 out of 100 runs, the result was accurate (with an RMSD below $2.0 \AA$ as compared to the X-ray structure). It should be emphasized that in all cases where the PM6 charge calculation was used, an accurate docking could be achieved (in one of the clusters there was a result with an RMSD below $2 \AA$ as compared to the X-ray) in contrast to the Gasteiger partial charge calculation dockings, where in eight cases no successful dockings were found (Table 2). The average RMSD of the first rank results is $1.71 \AA$ ( $1.61 \AA$ without outliers).

\section{Discussion}

The development of docking software that is able to accurately predict binding geometry and binding energy represents a great challenge in computational chemistry [68,71-73]. In the current study it was explored whether calculation of electrostatic potentials of both the ligands and the proteins using semi-empirical PM6 method increases docking accuracy. With the recent implementation of Mozyme, a PM6 semi-empirical method to the MOPAC2009 software [70], a semi-empirical calculation of partial charges on ligands as well as on larger molecules such as proteins has become possible; therefore, in our study semi-empirical charges were also computed on the protein as well as on the ligand atoms. In the course of the study, 53 experimentally determined protein-ligand complexes were chosen; the ligands were docked back to their host proteins with AutoDock 4 program using 1.) empirical Gasteiger method and 2.) semi-empirical PM6 method for calculating electrostatic potential. The results were then analyzed and compared to the experimentally determined crystal structure in order to evaluate docking accuracy. 
Table 2: Results of docking calculations using Gasteiger charges on both the ligand and the protein.

\begin{tabular}{|c|c|c|c|c|c|c|}
\hline $\begin{array}{l}\text { PDB code of the } \\
\text { complex }\end{array}$ & $\begin{array}{l}\text { RMSD of the } \\
\text { first rank result } \\
\text { as compared to } \\
\text { the X-ray }(\AA)\end{array}$ & $\begin{array}{c}\text { Energy rank of } \\
\text { the lowest } \\
\text { RMSD hit }\end{array}$ & $\begin{array}{l}\text { Frequency rankl } \\
\text { frequency of the } \\
\text { best geometry }\end{array}$ & $\begin{array}{c}\text { Lowest RMSD } \\
\text { (A) }\end{array}$ & $\begin{array}{c}\text { Estimated free } \\
\text { energy of } \\
\text { binding } \\
\text { (kcal/mol) }\end{array}$ & $\begin{array}{c}\text { Experimental } \\
\text { binding energy } \\
(\mathrm{kcal} / \mathrm{mol})\end{array}$ \\
\hline $\mid \mathrm{Al} 5$ & 1.21 & I & $1 / 48$ & 0.65 & -5.11 & -5.08 \\
\hline$\underline{I A J P}$ & 2.56 & 2 & $1 / 47$ & 1.09 & -4.40 & -3.05 \\
\hline IAMW & 1.68 & I & $|/ 2|$ & 1.59 & -5.62 & -6.19 \\
\hline IBGQ & 1.03 & I & $1 / 48$ & 0.71 & -6.27 & -11.69 \\
\hline$\underline{I C B R}$ & 1.00 & I & $\mid / 5 I$ & 0.92 & -7.94 & -10.58 \\
\hline$\underline{\text { ID3O }}$ & 2.68 & 2 & $2 / 19$ & 1.23 & -10.33 & -8.88 \\
\hline ID3T & 2.29 & 2 & $2 / 20$ & 1.08 & -10.08 & -8.73 \\
\hline IDWB & 9.59 & 3 & $\mid / 5 I$ & 0.53 & -6.24 & -3.98 \\
\hline IFLR & 0.60 & I & $1 / 100$ & 0.53 & -10.76 & -10.98 \\
\hline IGNI & 1.56 & I & $1 / 49$ & 1.10 & -7.73 & - \\
\hline$\underline{\text { HV }}$ & 3.12 & - & & & -10.03 & -14.27 \\
\hline$\underline{\text { IHVR }}$ & 0.65 & I & $1 / 26$ & 0.54 & -14.74 & -12.97 \\
\hline $1 \mathrm{~K} 4 \mathrm{G}$ & 2.82 & 4 & $1 / 30$ & 1.66 & -6.98 & -7.99 \\
\hline$\underline{\mid K V I}$ & 0.64 & I & $1 / 98$ & 0.56 & -8.91 & -8.10 \\
\hline$\underline{\text { ILIF }}$ & 2.33 & 4 & $|/ 2|$ & 1.08 & -5.47 & -9.65 \\
\hline IMON & 3.91 & - & & & -8.22 & -3.03 \\
\hline $1 \mathrm{MOQ}$ & 2.24 & 5 & $33 / 1$ & 1.46 & -5.99 & -5.30 \\
\hline$\underline{\text { IOLU }}$ & 1.34 & I & $4 / 10$ & 0.74 & -6.96 & -6.01 \\
\hline IQ8T & 1.88 & I & $1 / 77$ & 1.41 & -8.29 & -6.49 \\
\hline IRBP & 0.84 & I & $1 / 100$ & 0.56 & -9.15 & -9.17 \\
\hline$\underline{1539}$ & 4.29 & 2 & $2 / 11$ & 0.32 & -5.29 & -10.50 \\
\hline$\underline{1 \cup 33}$ & 2.49 & I & $2 / 14$ & 1.73 & -8.14 & -6.28 \\
\hline$\underline{\text { IULB }}$ & 1.88 & I & $1 / 100$ & 1.83 & -4.66 & -7.20 \\
\hline IUWT & 2.36 & I & $1 / 89$ & 0.87 & -6.77 & -8.14 \\
\hline$\underline{\mathrm{IX} 8 \mathrm{R}}$ & 1.24 & I & $1 / 80$ & 0.87 & -4.17 & -8.36 \\
\hline$|X D|$ & 2.92 & - & & & -11.12 & -10.80 \\
\hline$\underline{I Y D T}$ & 2.2 & 2 & $1 / 30$ & 0.74 & -10.14 & -9.98 \\
\hline
\end{tabular}


Table 2: Results of docking calculations using Gasteiger charges on both the ligand and the protein. (Continued)

\begin{tabular}{|c|c|c|c|c|c|c|}
\hline$\underline{\text { IZC9 }}$ & 2.71 & - & & & -4.00 & -4.39 \\
\hline$\underline{2 A C K}$ & 3.96 & 8 & $8 / 1$ & 1.07 & -4.72 & -8.97 \\
\hline 2BAJ & 0.68 & I & $1 / 74$ & 0.42 & -12.40 & -11.46 \\
\hline$\underline{2 B A K}$ & 1.28 & I & $16 / 2$ & 1.28 & -13.78 & -10.14 \\
\hline 2CEQ & 7.14 & - & & & -4.66 & -9.92 \\
\hline$\underline{2 \text { CET }}$ & 4.86 & - & & & -7.06 & -10.94 \\
\hline$\underline{2 C G R}$ & 0.87 & I & $1 / 43$ & 0.50 & -10.68 & -9.89 \\
\hline$\underline{2 \mathrm{CPP}}$ & 1.56 & I & $1 / 100$ & 1.21 & -6.35 & -8.28 \\
\hline$\underline{2 D 3 U}$ & 0.87 & I & I/58 & 0.83 & -9.43 & -9.44 \\
\hline$\underline{2 \mathrm{D} 3 Z}$ & 4.68 & 3 & $2 / 20$ & 0.69 & -8.89 & -9.06 \\
\hline$\underline{2 \mathrm{FDP}}$ & 2.35 & 5 & $73 / 1$ & 1.68 & -13.67 & -10.35 \\
\hline$\underline{2 \mathrm{G} 94}$ & 3.13 & - & & & -7.57 & -12.99 \\
\hline$\underline{2 \mathrm{GBP}}$ & 0.99 & I & $1 / 90$ & 0.92 & -4.18 & -10.37 \\
\hline$\underline{\text { 2IFB }}$ & 2.03 & 2 & $1 / 45$ & 1.10 & -6.03 & -7.41 \\
\hline$\underline{2 I W X}$ & 0.88 & I & $1 / 68$ & 0.55 & -6.66 & -9.11 \\
\hline 2J777 & 1.9 & I & $1 / 100$ & 1.85 & -7.52 & -6.67 \\
\hline 2]78 & 0.83 & I & $2 / 11$ & 0.83 & -6.41 & -8.75 \\
\hline 2QFU & 2.75 & 3 & $3 / 1$ & 1.02 & -6.29 & -5.70 \\
\hline 2QWB & 4.38 & 13 & $6 / 5$ & 1.17 & -5.40 & -3.74 \\
\hline 2QWD & 1.36 & I & $1 / 54$ & 0.97 & -6.80 & -6.62 \\
\hline$\underline{2 R 04}$ & 2.06 & 2 & $3 / 21$ & 1.02 & -8.97 & -8.87 \\
\hline$\underline{2 X I S}$ & 1.20 & I & $1 / 95$ & 1.15 & -5.43 & -7.94 \\
\hline$\underline{2 Y P I}$ & 4.73 & - & & & -3.09 & -6.57 \\
\hline$\underline{\text { PPTB }}$ & 1.35 & I & $1 / 100$ & 0.51 & -5.66 & -6.47 \\
\hline$\underline{4 \mathrm{HMG}}$ & 1.82 & I & $1 / 22$ & 1.02 & -4.78 & -3.48 \\
\hline$\underline{7 A B P}$ & 2.15 & 2 & $2 / 13$ & 1.64 & -4.58 & -8.78 \\
\hline
\end{tabular}

$\begin{gathered}\text { Average: } 2.34 \\ \text { without outliers } \\ \text { (rmsd above } 4\end{gathered}$

A): 1.83

The average value of the RMSD between the lowest energy result and experimental structure and the total number of successful first rank predictions (based on lowest energy and highest cluster population, respectively) are indicated at the bottom of the table. 
Table 3: Results of docking calculations using semi-empirical charges on both the ligand and the protein.

\begin{tabular}{|c|c|c|c|c|c|c|}
\hline $\begin{array}{l}\text { PDB code of the } \\
\text { complex }\end{array}$ & $\begin{array}{l}\text { RMSD of the } \\
\text { first rank result } \\
\text { as compared to } \\
\text { the X-ray }(\AA)\end{array}$ & $\begin{array}{c}\text { Energy rank of } \\
\text { the lowest } \\
\text { RMSD hit }\end{array}$ & $\begin{array}{c}\text { Frequency rank/ } \\
\text { frequency of the } \\
\text { best geometry }\end{array}$ & $\begin{array}{c}\text { Lowest RMSD } \\
(\AA)\end{array}$ & $\begin{array}{l}\text { Estimated free } \\
\text { energy of } \\
\text { binding } \\
\text { (kcal/mol) }\end{array}$ & $\begin{array}{c}\text { Experimental } \\
\text { binding energy } \\
(\mathrm{kcal} / \mathrm{mol})\end{array}$ \\
\hline$\underline{|A| 5}$ & 1.22 & I & $1 / 100$ & 0.65 & -5.06 & -5.08 \\
\hline$\underline{I A J P}$ & 2.73 & 2 & $1 / 97$ & 1.07 & -4.82 & -3.05 \\
\hline IAMW & 2.13 & I & $1 / 35$ & 0.87 & -5.67 & -6.19 \\
\hline IBGQ & 1.03 & I & $1 / 100$ & 0.70 & -6.50 & -11.69 \\
\hline$\underline{I C B R}$ & 1.01 & I & $1 / 93$ & 0.77 & -7.42 & -10.58 \\
\hline$\underline{\text { ID3Q }}$ & 2.77 & 2 & $2 / 40$ & 0.85 & -11.47 & -8.88 \\
\hline$\underline{\text { ID3T }}$ & 2.09 & 3 & $1 / 60$ & 0.99 & -10.37 & -8.73 \\
\hline IDWB & 0.72 & I & $1 / 100$ & 0.54 & -4.87 & -3.98 \\
\hline$\underline{\text { IFLR }}$ & 0.39 & I & $1 / 100$ & 0.39 & -8.54 & -10.98 \\
\hline$\underline{\mathrm{IGNI}}$ & 3.01 & 2 & $1 / 69$ & 1.01 & -6.80 & $-|1.0|$ \\
\hline 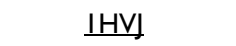 & 1.61 & I & $1 / 5$ & 1.61 & -10.45 & -14.27 \\
\hline$\underline{\mathrm{IHVR}}$ & 1.21 & I & $1 / 96$ & 1.00 & -11.67 & -12.97 \\
\hline$\underline{\mathrm{K}} 4 \mathrm{G}$ & 2.83 & 4 & $1 / 89$ & 1.42 & -7.78 & -7.99 \\
\hline$\underline{|K V|}$ & 0.6 & $\mathbf{I}$ & $1 / 100$ & 0.58 & -9.33 & -8.10 \\
\hline$\underline{\text { ILIF }}$ & 3.1 & 4 & $3 / 17$ & 0.93 & -4.51 & -9.65 \\
\hline IMON & 1.18 & I & $1 / 86$ & 1.02 & -7.65 & -3.03 \\
\hline $1 \mathrm{MOQ}$ & 1.03 & I & $1 / 80$ & 0.95 & -7.15 & -5.30 \\
\hline$\underline{\text { IOLU }}$ & 0.89 & I & $1 / 89$ & 0.61 & -9.14 & -6.01 \\
\hline IQ8T & 1.9 & I & $1 / 100$ & 1.41 & -7.58 & -6.49 \\
\hline$\underline{\text { IRBP }}$ & 0.85 & I & $1 / 100$ & 0.56 & -8.46 & -9.17 \\
\hline$\underline{1539}$ & 4.29 & 2 & $1 / 95$ & 0.33 & -4.65 & -10.50 \\
\hline$\underline{\operatorname{IU} 33}$ & 0.86 & $\mathbf{I}$ & $1 / 43$ & 0.80 & -9.82 & -6.28 \\
\hline$\underline{\text { IULB }}$ & 0.7 & I & $1 / 100$ & 0.64 & -5.09 & -7.20 \\
\hline$\underline{I U W T}$ & 2.35 & I & $1 / 53$ & 0.71 & -6.47 & -8.14 \\
\hline$\underline{\mathrm{IX} 8 \mathrm{R}}$ & 1.26 & I & $1 / 100$ & 0.96 & -3.10 & -8.36 \\
\hline$|X D|$ & 1.81 & I & $2 / 10$ & 1.30 & -15.97 & -10.80 \\
\hline$\underline{I Y D T}$ & 0.79 & I & $1 / 93$ & 0.45 & -8.05 & -9.98 \\
\hline
\end{tabular}


Table 3: Results of docking calculations using semi-empirical charges on both the ligand and the protein. (Continued)

\begin{tabular}{|c|c|c|c|c|c|c|}
\hline$\underline{\text { IZC9 }}$ & 2.7 & 14 & $2 / 26$ & 0.96 & -6.76 & -4.39 \\
\hline$\underline{2 A C K}$ & 3.98 & 4 & $2 / 22$ & 0.94 & -5.25 & -8.97 \\
\hline 2BAJ & 0.66 & I & $1 / 100$ & 0.55 & -12.50 & -11.46 \\
\hline$\underline{2 B A K}$ & 1.21 & I & 1/98 & 0.64 & -14.20 & -10.14 \\
\hline 2CEQ & 0.85 & I & $1 / 44$ & 0.83 & -6.23 & -9.92 \\
\hline$\underline{2 \text { CET }}$ & 2.61 & I & $2 / 15$ & 0.96 & -7.76 & -10.94 \\
\hline$\underline{2 C G R}$ & 0.9 & I & $1 / 100$ & 0.68 & -10.05 & -9.89 \\
\hline$\underline{2 \mathrm{CPP}}$ & 1.21 & I & $1 / 100$ & 1.21 & -6.26 & -8.28 \\
\hline$\underline{2 D 3 U}$ & 0.68 & I & $1 / 100$ & 0.54 & -7.11 & -9.44 \\
\hline$\underline{2 \mathrm{D} 3 Z}$ & 3.86 & 3 & $1 / 88$ & 0.63 & -7.60 & -9.06 \\
\hline$\underline{2 \mathrm{FDP}}$ & 0.75 & I & 1/89 & 0.68 & -14.80 & -10.35 \\
\hline$\underline{2 \mathrm{G} 94}$ & 1.75 & I & $3 / 5$ & 1.45 & -8.64 & -12.99 \\
\hline$\underline{2 \mathrm{GBP}}$ & 0.89 & I & $1 / 100$ & 0.87 & -5.60 & -10.37 \\
\hline$\underline{\text { 2IFB }}$ & 2.05 & 2 & I/55 & 1.03 & -4.99 & -7.41 \\
\hline$\underline{2 I W X}$ & 0.87 & I & $1 / 100$ & 0.55 & -6.76 & -9.11 \\
\hline 2]77 & 2.01 & $I$ & $1 / 93$ & 1.60 & -7.62 & -6.67 \\
\hline 2]78 & 0.83 & I & $2 / 27$ & 0.73 & -6.13 & -8.75 \\
\hline 2QFU & 2.74 & 4 & $2 / 37$ & 0.94 & -6.29 & -5.70 \\
\hline 2QWB & 4.35 & 12 & $2 / 15$ & 0.90 & -6.64 & -3.74 \\
\hline 2QWD & 2.57 & 2 & $1 / 67$ & 0.91 & -7.37 & -6.62 \\
\hline$\underline{2 R 04}$ & 1.99 & 2 & $2 / 8$ & 0.92 & -8.84 & -8.87 \\
\hline$\underline{2 X I S}$ & 1.17 & I & $1 / 100$ & 1.14 & -6.93 & -7.94 \\
\hline$\underline{2 Y P I}$ & 1.19 & I & $1 / 61$ & 0.78 & -2.62 & -6.57 \\
\hline$\underline{\text { PPTB }}$ & 1.31 & I & $1 / 100$ & 0.74 & -5.06 & -6.47 \\
\hline$\underline{4 \mathrm{HMG}}$ & 1.04 & I & 1/98 & 0.85 & -6.92 & -3.48 \\
\hline$\underline{7 A B P}$ & 2.09 & I & 1/97 & 1.16 & -5.58 & -8.78 \\
\hline
\end{tabular}

$\begin{aligned} & \text { Average: } 1.71 \\ & \text { without outliers } \\ & \text { (rmsd above } 4\end{aligned}$

A): 1.61

QASP parameter was modified from 0.01097 to 0.00679 in AutoGrid and AutoDock. The average value of the RMSD between the lowest energy result and experimental structure and the total number of successful first rank predictions (based on lowest energy and highest cluster population, respectively) are indicated at the bottom of the table. 
It is important to note that AutoDock 4 scoring function which is used both during and at the end of the dockings thus influencing both the geometry and binding energy estimation - was optimized using the Gasteiger charge calculation method. Since the semi-empirical PM6 calculation method gives higher absolute value for partial charge on a selected atom than the empirical Gasteiger method (Figure 2), each term in the AutoDock equation was carefully considered for expected changes as a result of the semi-empirical method used for partial charge calculation before carrying out docking calculations. Besides the electrostatic term, which is naturally expected to change, absolute values of partial charges are included in the solvation term (Scheme 1) [14].

In order to achieve accurate intermolecular energy calculation, the solvation term should not change as a result of the use of different methods for partial charge calculation. Therefore, the extent of change in the absolute value of partial charges using Gasteiger and PM6 methods were analyzed. Our results showed that the partial charges calculated with the Gasteiger method were on average 0.619

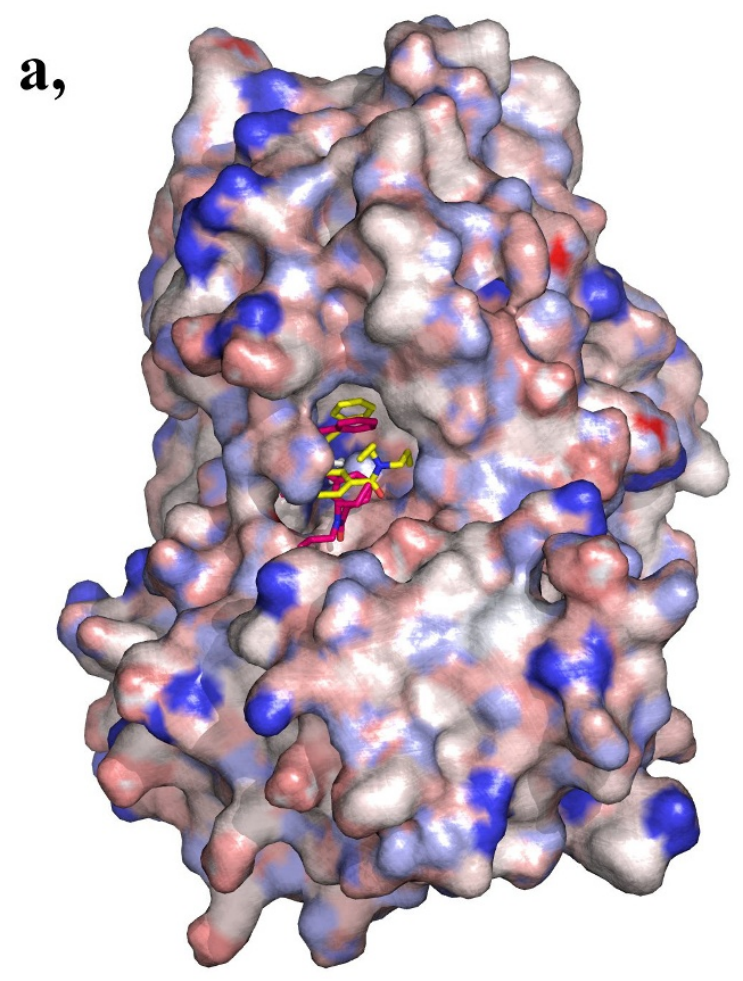

times lower than the ones calculated with Mozyme, thus, the QASP parameter was reduced by 0.619 . This way the solvation term in the energy calculation of AutoDock 4 has not changed as a result of semi-empirical partial charge calculation.

Our docking results showed that as a consequence of the partial charge calculation with the PM6 method, a dramatic increase was observed in 1.) the number of accurate dockings (i.e. ligand's RMSD is within $2 \AA$ of the actual Xray structure 2.) population of clusters with the accurate docking result. However, the accuracy of the binding energy prediction has not increased.

The latter finding is not surprising because of several reasons: Although the electrostatic term for a given atom pair is greatly increased when the semi-empirical PM6 method is used for charge calculation compared to Gasteiger charge calculation, this increase is equally present for both negatively and positively charged atoms. Thus, as the positively and negatively charged atoms partly extinguish, and the final electrostatic term summed up for all ligand

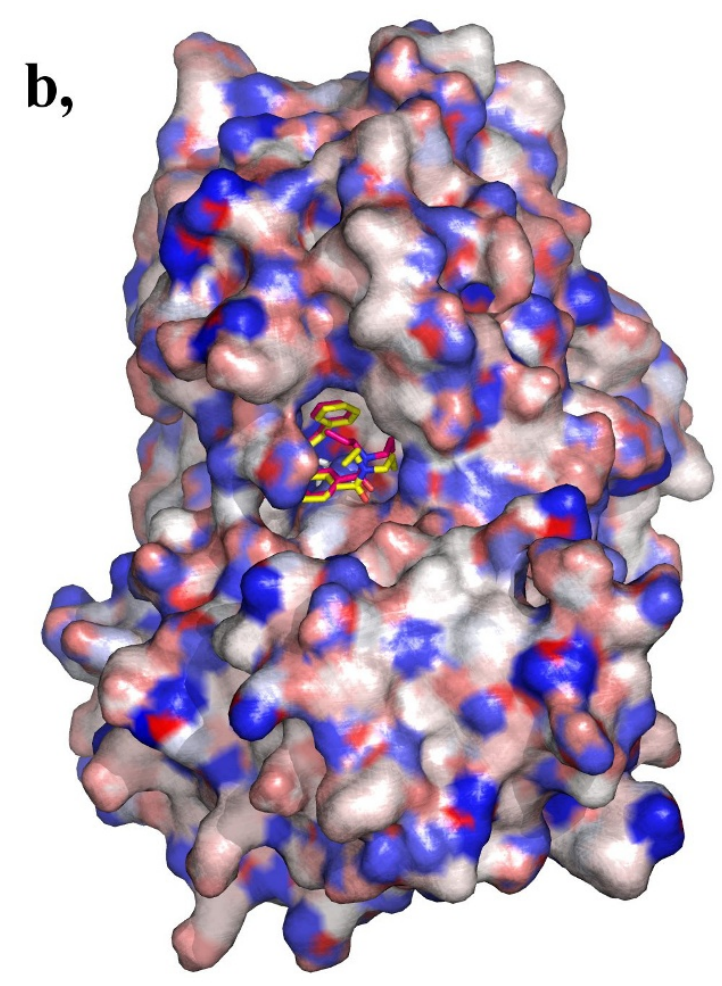

\section{Figure 2}

Best cluster rank docking results of redocking of the PDB entry 2FDP. Protein surfaces are colored by partial charges (a, PM6 charges, RMSD from coordinates in PDB: 0.75 b, Gasteiger charges, RMSD from coordinates in PDB: 2.35). The darker color of the protein surface colored by PM6 partial charges as compared to the colors of Figure $2 b$ reflects the higher calculated absolute value of semi-empirical partial charges. This "sharper" surface defines the possible binding geometry of the ligand more, than in the case of Gasteiger charges. 
atoms; the energy related to the electrostatic term will not change to a great extent causing only a minor change in binding energy estimation. Additionally, the weighting constants of these terms in AutoDock 4 were optimized using the Gasteiger charge calculation method; therefore, the final energy calculation is not expected to give a more accurate result using the current weighting constants in the scoring function. Moreover, the method used for partial charge calculation does not influence the torsional entropy term of the equation, which is one of the limiting factors in the accuracy of binding energy estimation in the AutoDock 4 program [74]. In addition, considering the high number of false positives in docking calculations, it is reasonable to assume that in addition to stabilizing contributions, there are destabilizing contributions to $\Delta \mathrm{G}$ which are in most scoring functions not taken into account [75].

The dramatic change in the number of accurate docking poses is a significant achievement. As discussed above, the electrostatic term for a given atom pair is greatly increased when the semi-empirical PM6 method is used for charge calculation compared to Gasteiger charge calculation and this change is present at different extents in case of each atom type. Thus, a "sharper" electrostatic potential is present using the PM6 method for calculating partial charges (Figure 2) as compared to the Gasteiger charge calculation method. This results in a more pronounced significance of the electrostatic interactions between each atomic pair leading to a more defined protein-ligand complex geometry as compared to the original method where Gasteiger calculation is used.

The high population of clusters with the correct geometry with the PM6 charge calculation method is also of great significance (Figure 3). Namely, high cluster population hints at the density of states for a given complex conformation. If the energy of that state does not substantially differ from the lowest binding energy $(2.5 \mathrm{kcal} / \mathrm{mol}$ is within the standard deviation of the AutoDock 4 force field) then the higher cluster population is indicative of a more probable conformation. This is important information when no experimental data exist as to where the ligand is bound. In conclusion, the use of the PM6 method for calculating partial charges has resulted in a significantly better prediction of docking geometry and in the cluster population of the right docking pose.

Besides accurate binding energy estimation, a measure of docking accuracy is a good geometry, i.e. low RMSD value of the docked ligand as compared to the crystal structure. A recent study [13] reports that developing a scoring function that predicts binding energy with good accuracy is not necessarily achieved by optimizing binding geometry. However, in our study, the correlation coefficient between the experimentally determined and calculated binding energies increased by considering only the hits where the first rank result yielded an RMSD within $2 \AA$ of the actual $\mathrm{X}$-ray structure in docking calculation. Thus, our results indicated that good geometry prediction is indeed prerequisite for accurate binding energy estimation. Although the optimization of AutoDock 4 scoring function was outside the scope of the current study, the fact that significantly more accurate protein-ligand complex geometry prediction is achieved using the PM6 method hints at the possibility of more accurate binding energy estimation using PM6 charge calculation as well.

AutoDockTools, a software used for setting up ligands and proteins for use in AutoDock 4, one of the most popular docking softwares on market [11], is using the empirical Gasteiger method for calculating partial charges for protein and ligand setup. The Gasteiger charge calculation method is based on the partial equalization of orbital electronegativity $[17,76]$. In the calculation only the topology of the molecule is considered, as only the connectivity of the atoms are included in the calculation. The calculation of electrostatic potential with empirical methods have the advantage of being fast, however, they possess some drawbacks as well: the Gasteiger charge calculation method as opposed to the semi-empirical PM6 method, does not handle inorganic compounds such as metal ions, frequently present in functional proteins. In a study using semi-empirical electronic wave functions like AM1 and PM3 to map experimental dipole moments for a large number of small molecules, the dipole moments were reproduced with a root mean square deviation of $0.3 \mathrm{D}$ [77]. It has been shown based on a large validation set that semi-empirical methods are highly accurate in partial charge calculations and are able to reproduce experimental homo- and hetero-dimer hydrogen-bond energies [16]. Moreover, a number of papers have been published that report increased docking accuracy using the semi-empirical method for partial charge calculation of the ligand atoms $[15,22,76]$. Indeed, in a recent study comparing several partial charge calculation methods, semi-empirical charge calculation has been shown to increase docking accuracy compared to the use of empirical methods [15]. In that study, partial charge calculation of the ligand alone with the semi-empirical method was sufficient to slightly increase docking accuracy (the protein partial charges were still computed with the Gasteiger method). Quantum mechanical charge calculations on proteins are not very common because of the highly time consuming calculation. One possibility is to consider the effect of the protein binding site on the ligand polarization using quantum chemical methods $[19,20]$. However, this method still limits the quantum mechanical charge calculations on the ligand and it is difficult to apply when the complex structure is not known. 


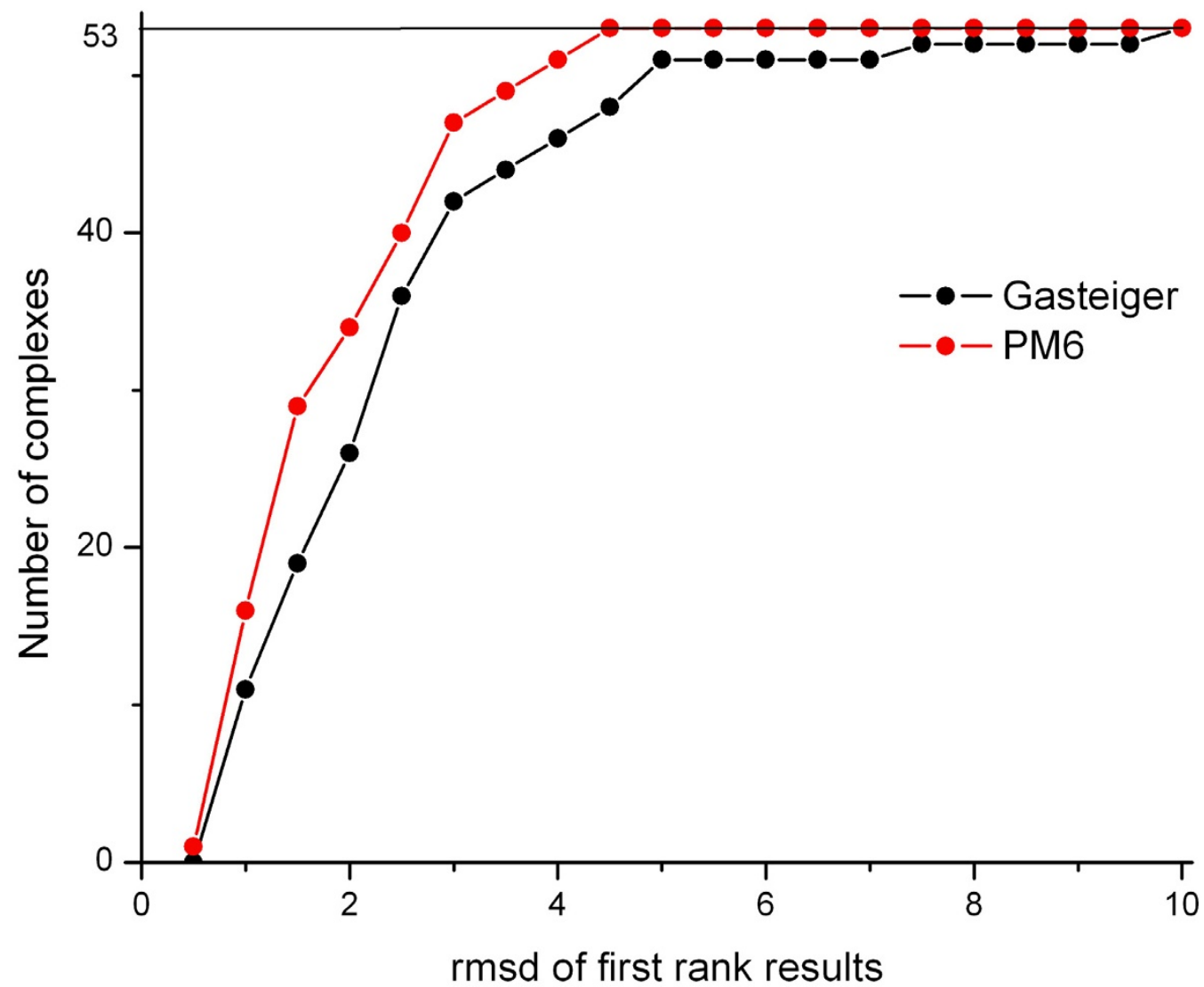

Figure 3

Performance of the PM6 charge calculation in docking experiments, compared to Gasteiger method. The graph shows the number of complexes within a given RMSD of the crystallographic structure. In each case, the conformation of the most favorable estimated energy is used as the predicted conformation.

Calculation of quantum mechanical charges using the recent linear scaling Mozyme functionality of MOPAC2009 [23] allows us to calculate quantum chemical charges on protein atoms, as well. Our results suggest that calculation of PM6 charges on protein atoms has an even more profound effect on the docking accuracy.

\section{Conclusion}

In summary, our study explored the effect of the partial charge calculation method on docking accuracy calculated using AutoDock 4 software. To the author's knowledge this is the first systematic docking study where the semiempirical quantum chemical PM6 method is used for partial charge calculation on the protein as well as on the ligand. Partial charge calculation with the PM6 method has been shown to greatly increase docking accuracy and cluster population of the most accurate docking; however, no increase in the accuracy of binding energy estimation was observed. As a good pose of the ligand seems to be prerequisite for accurate intermolecular energy prediction, the use of the PM6 method presents a great improvement in the accuracy of docking calculations carried out using AutoDock 4. If the PM6 semi-empirical method is used for partial charge calculation, reoptimization of the weighting constants of AutoDock 4 scoring function is needed in order to increase the accuracy of binding energy estimation as well.

\section{Methods}

Crystal structures of the protein-ligand complexes used in this study were obtained from the Brookhaven Protein DataBank http://www.rcsb.org/pdb. When the asymmetric unit was found to differ from the biological unit, the ligand binding site was carefully checked. When the ligand was found to interact with more than one asymmetric units, the biological unit was used in the study (in cases of proteins with PDB code: 1OLU, 2XIS). Experimental binding affinities for the protein-ligand complexes were taken from the PDBBind Database [69]. The proteins and ligands used in this study were all formerly used as a test 
set in recently published papers $[13,68]$ or were taken from the PDB core set [69]. The structures were chosen in order to meet the following criteria: structurally diverse ligands in complex with a heterogeneous collection of proteins; non-covalent binding between protein and ligand and crystallographic resolution lower than $3.2 \AA$.

All docking studies described here involved flexible docking of the ligand to the rigid receptor, both of which were derived from the complex crystal structure. Input structures were prepared by using two different methods: (i), using Gasteiger charges for both the ligands and the proteins [17]; (ii), using PM6 charges calculated by MOPAC2009 [70] for both the ligands and the proteins. Briefly, the input structures with Gasteiger charges were prepared as follows: The ligand atom types and bond types were assigned and hydrogens were added using AutoDockTools. Empirical charges were calculated with the method of Gasteiger [17]. For proteins, co-factors, such as HEME and metal ions were kept, and their atom types and bond types were assigned manually. Sulfate, halogens and water molecules were removed. Hydrogens were added in protein residues as well as Gasteiger partial charges using AutoDockTools. Non-polar hydrogens were merged and their charges were added to the heavy atoms. No additional optimization of the protein structures was carried out.

Semi-empirical assignments were performed using the PM6 method by the Mozyme function of MOPAC2009 program [70] integrated in Docking Server http:// www.dockingserver.com. Ligand structures with semiempirical charges were setup similarly as described above, except that in the last step PM6 charges were calculated using MOPAC2009 software. Protein structures were setup as follows: First, water molecules, sulfate, and halogens were removed. Hydrogen atoms were added to the pdb structures using AutoDockTools. The total charge of the protein and partial charges of the atoms were calculated by the Mozyme function of MOPAC2009 software. The calculated partial charges were applied for further calculations.

Docking studies were subsequently performed using Docking Server http://www.dockingserver.com. Docking Server integrates Marvin http://www.chemaxon.com and MOPAC2009 during ligand set up in order to calculate partial charges at a given protonation state and for semiempirical geometry optimization; and AutoDock 4 is integrated [14] for docking calculation. In cases where protein and ligand partial charges were calculated with the PM6 method, the QASP parameter was modified (QASP = 0.00679) and used in Autogrid 4 and AutoDock 4 during docking calculations (see Results section for detailed explanation).
Briefly, the following parameters were set in Docking Server: Grid parameter files were built and atom-specific affinity maps were constructed using Autogrid 4 [14]. These map files were generated using $60 \times 60 \times 60$ grid points and $0.375 \AA$ spacing, with the maps centered on the experimentally determined center of the bound ligand. Docking simulations for the study were carried out using the Lamarckian Genetic Algorithm. The initial position, orientation, and torsions of the ligand molecules were set randomly, and all rotatable torsions were released during docking. Each docking experiment was derived from 100 different runs that were set to terminate after a maximum of 2,500,000 energy evaluations and had a population size of 250 . After each docking calculation, the RMSD between the lowest energy docked ligand pose and the complex crystal structure ligand pose was evaluated.

\section{Competing interests}

The authors declare that they have no competing interests.

\section{Authors' contributions}

Both $\mathrm{ZB}$ and EH participated in the design of this study, as well as performing molecular docking and quantum chemical calculations. Both authors participated in manuscript preparation and read and approved the final manuscript.

\section{References}

I. Halperin I, Ma BY, Wolfson H, Nussinov R: Principles of docking: An overview of search algorithms and a guide to scoring functions. Proteins-Structure Function and Genetics 2002, 47(4):409-443.

2. Brooijmans N, Kuntz ID: Molecular recognition and docking algorithms. Annual Review of Biophysics and Biomolecular Structure 2003, 32:335-373.

3. Goodsell DS, Morris GM, Olson AJ: Automated docking of flexible ligands: Applications of AutoDock. J Mol Recognit 1996, 9(I): I-5.

4. Osterberg F, Morris GM, Sanner MF, Olson AJ, Goodsell DS: Automated docking to multiple target structures: Incorporation of protein mobility and structural water heterogeneity in AutoDock. Proteins-Structure Function and Bioinformatics 2002, 46(I):34-40.

5. Verdonk ML, Cole JC, Hartshorn MJ, Murray CW, Taylor RD: Improved protein-ligand docking using GOLD. Proteins-Structure Function and Genetics 2003, 52(4):609-623.

6. Verdonk ML, Chessari G, Cole JC, Hartshorn MJ, Murray CW, Nissink JWM, Taylor RD, Taylor R: Modeling water molecules in protein-ligand docking using GOLD. Journal of Medicinal Chemistry 2005, 48(20):6504-65।5.

7. Halgren TA, Murphy RB, Friesner RA, Beard HS, Frye LL, Pollard WT, Banks JL: Glide: A new approach for rapid, accurate docking and scoring. 2. Enrichment factors in database screening. Journal of Medicinal Chemistry 2004, 47(7): I750- 1759.

8. Friesner RA, Banks JL, Murphy RB, Halgren TA, Klicic JJ, Mainz DT, Repasky MP, Knoll EH, Shelley M, Perry JK, Shaw DE, Francis P, Shenkin PS: Glide: A new approach for rapid, accurate docking and scoring. I. Method and assessment of docking accuracy. Journal of Medicinal Chemistry 2004, 47(7): 1739-1749.

9. Kramer B, Rarey M, Lengauer T: CASP2 experiences with docking flexible ligands using FLEXX. Proteins-Structure Function and Genetics 1997:221-225. 
10. Kramer B, Rarey M, Lengauer T: Evaluation of the FLEXX incremental construction algorithm for protein-ligand docking. Proteins-Structure Function and Genetics 1999, 37(2):228-24I.

II. Sousa SF, Fernandes PA, Ramos MJ: Protein-ligand docking: Current status and future challenges. Proteins-Structure Function and Bioinformatics 2006, 65(I): 15-26.

12. Warren GL, Andrews CW, Capelli AM, Clarke B, LaLonde J, Lambert MH, Lindvall M, Nevins N, Semus SF, Senger S, Tedesco G, Wall ID, Woolven JM, Peishoff CE, Head MS: A critical assessment of docking programs and scoring functions. Journal of Medicinal Chemistry 2006, 49(20):5912-5931.

13. Spyrakis F, Amadasi A, Fornabaio M, Abraham DJ, Mozzarelli A, Kellogg GE, Cozzini P: The consequences of scoring docked ligand conformations using free energy correlations. Eur J Med Chem 2007, 42(7):921-933.

14. Huey R, Morris GM, Olson AJ, Goodsell DS: A semiempirical free energy force field with charge-based desolvation. I Comput Chem 2007, 28(6): I |45-I I52.

15. Tsai KC, Wang SH, Hsiao NW, Li M, Wang B: The effect of different electrostatic potentials on docking accuracy: a case study using DOCK5.4. Bioorg Med Chem Lett 2008, I 8(12):3509-35I2.

16. Jakalian A, Jack DB, Bayly Cl: Fast, efficient generation of highquality atomic charges. AMI-BCC model: II. Parameterization and validation. J Comput Chem 2002, 23(16): |623-164I.

17. Gasteiger J, Marsili M: Iterative Partial Equalization of Orbital Electronegativity - a Rapid Access to Atomic Charges. Tetrahedron 1980, 36(22):3219-3228.

18. Mobley DL, Graves AP, Chodera JD, McReynolds AC, Shoichet BK, Dill KA: Predicting absolute ligand binding free energies to a simple model site. J Mol Biol 2007, 37 I(4): I II8-II34.

19. Cho AE, Guallar V, Berne BJ, Friesner R: Importance of accurate charges in molecular docking: quantum mechanical/molecular mechanical (QM/MM) approach. J Comput Chem 2005, 26(9):9|5-93|.

20. Illingworth CJ, Morris GM, Parkes KE, Snell CR, Reynolds CA: Assessing the role of polarization in docking. J Phys Chem $A$ 2008, I I 2(47): 12157-12163.

21. Ponder JW, Case DA: Force fields for protein simulations. $A d v$ Protein Chem 2003, 66:27-85.

22. Raha K, Merz KM Jr: Large-scale validation of a quantum mechanics based scoring function: predicting the binding affinity and the binding mode of a diverse set of protein-ligand complexes. J Med Chem 2005, 48(14):4558-4575.

23. Stewart J]: Application of the PM6 method to modeling proteins. J Mol Model 2009.

24. Done SH, Brannigan JA, Moody PCE, Hubbard RE: Ligand-induced conformational change in penicillin acylase. J Mol Biol 1998, 284(2):463-475.

25. Prodromou C, Roe SM, Obrien R, Ladbury JE, Piper PW, Pearl LH: Identification and structural characterization of the ATPI ADP-binding site in the Hsp90 molecular chaperone. Cell 1997, 90(I):65-75.

26. Roe SM, Prodromou C, O'Brien R, Ladbury JE, Piper PW, Pearl LH: Structural basis for inhibition of the Hsp90 molecular chaperone by the antitumor antibiotics radicicol and geldanamycin. Journal of Medicinal Chemistry 1999, 42(2):260-266.

27. Kleywegt GJ, Bergfors T, Senn H, Le Motte P, Gsell B, Shudo K, Jones TA: Crystal structures of cellular retinoic acid binding proteins I and II in complex with all-trans-retinoic acid and a synthetic retinoid. Structure 1994, 2( I 2): | 24|-|258.

28. Chirgadze NY, Sall DJ, Briggs SL, Clawson DK, Zhang M, Smith GF, Schevitz RW: The crystal structures of human alpha-thrombin complexed with active site-directed diamino benzo[b]thiophene derivatives: a binding mode for a structurally novel class of inhibitors. Protein Sci 2000, 9(1):29-36.

29. Banner DW, Hadvary P: Crystallographic Analysis at 3.0-a Resolution of the Binding to Human Thrombin of 4 Active SiteDirected Inhibitors. Journal of Biological Chemistry I991, 266(30):20085-20093.

30. Whitlow M, Howard AJ, Wood JF, Voss EW Jr, Hardman KD: I.85 A structure of anti-fluorescein 4-4-20 Fab. Protein Eng 1995, 8(8):749-76I.

31. Petitpas I, Grune T, Bhattacharya AA, Curry S: Crystal structures of human serum albumin complexed with monounsaturated and polyunsaturated fatty acids. I Mol Biol 200I, 3 I 4(5): $955-960$.

32. Hosur MV, Bhat TN, Kempf DJ, Baldwin ET, Liu BS, Gulnik S, Wideburg NE, Norbeck DW, Appelt K, Erickson JW: Influence of Stereochemistry on Activity and Binding Modes for $\mathbf{C}(2)$ Symmetry-Based Diol Inhibitors of Hiv-I Protease. Journal of the American Chemical Society 1994, I I 6(3):847-855.

33. Lam PYS, Jadhav PK, Eyermann CJ, Hodge CN, Ru Y, Bacheler LT, Meek JL, Otto MJ, Rayner MM, Wong YN, Chang CH, Weber PC, Jackson DA, Sharpe TR, Erickson-Viitanen S: Rational Design of Potent, Bioavailable, Nonpeptide Cyclic Ureas as Hiv Protease Inhibitors. Science 1994, 263(5 I 45):380-384.

34. Meyer EA, Brenk R, Castellano RK, Furler M, Klebe G, Diederich F: De novo design, synthesis, and in vitro evaluation of inhibitors for prokaryotic tRNA-guanine transglycosylase: A dramatic sulfur effect on binding affinity. Chembiochem 2002, 3(23):250-253.

35. Pargellis C, Tong L, Churchill L, Cirillo PF, Gilmore T, Graham AG, Grob PM, Hickey ER, Moss N, Pav S, Regan J: Inhibition of p38 MAP kinase by utilizing a novel allosteric binding site. Nature Structural Biology 2002, 9(4):268-272.

36. Xu Z, Bernlohr DA, Banaszak LJ: The adipocyte lipid-binding protein at I.6-A resolution. Crystal structures of the apoprotein and with bound saturated and unsaturated fatty acids. J Biol Chem 1993, 268(I I):7874-7884.

37. Liu WS, Rogers CJ, Fisher AJ, Toney MD: Arninophosphonate inhibitors of dialkylglycine decarboxylase: Structural basis for slow binding inhibition. Biochemistry 2002, 4I(4I): I 2320- | 2328 .

38. Wynn RM, Machius M, Chuang JL, Li J, Tomchick DR, Chuang DT: Roles of His(29I)-alpha and His( 146$)$-beta ' in the reductive acylation reaction catalyzed by human branched-chain alpha-ketoacid dehydrogenase - Refined phosphorylation loop structure in the active site. Journal of Biological Chemistry 2003, 278(44):43402-434I0.

39. Breitenlechner C, Gassel M, Hidaka H, Kinzel V, Huber R, Engh RA, Bossemeyer D: Protein kinase a in complex with rho-kinase inhibitors Y-2 fasudil, and H-I I 52P: Structural basis of selectivity. Structure 7632, I I(I 2): 1595-1607.

40. Cowan SW, Newcomer ME, Jones TA: Crystallographic Refinement of Human Serum Retinol Binding-Protein at 2a Resolution. Proteins-Structure Function and Genetics 1990, 8(I):44-6I.

4I. Meyer EA, Furler M, Diederich F, Brenk R, Klebe G: Synthesis and in vitro evaluation of 2-aminoquinazolin-4(3H)-one-based inhibitors for tRNA-Guanine transglycosylase (TGT). Helvetica Chimica Acta 2004, 87(6): I333-1356.

42. Numao S, Damager I, Li CM, Wrodnigg TM, Begum A, Overall CM, Brayer GD, Withers SG: In situ extension as an approach for identifying novel alpha-amylase inhibitors. Journal of Biological Chemistry 2004, 279(46):48282-4829I.

43. Ealick SE, Babu YS, Bugg CE, Erion MD, Guida WC, Montgomery JA, Secrist JA 3rd: Application of crystallographic and modeling methods in the design of purine nucleoside phosphorylase inhibitors. Proc Natl Acad Sci USA I 99 I, 88(24): I I540-I I 544.

44. Gloster TM, Roberts S, Ducros VMA, Perugino G, Rossi M, Hoos R, Moracci M, Vasella A, Davies G]: Structural studies of the betaglycosidase from Sulfolobus solfataricus in complex with covalently and noncovalently bound inhibitors. Biochemistry 2004, 43(20):610I-6109.

45. Priestman MA, Healy ML, Becker A, Alberg DG, Bartlett PA, Lushington $\mathrm{GH}$, Schonbrunn E: Interaction of phosphonate analogues of the tetrahedral reaction intermediate with 5-enolpyruvylshikimate-3-phosphate synthase in atomic detail. Biochemistry 2005, 44(9):324I-3248.

46. Li CM, Begum A, Numao S, Park KH, Withers SG, Brayer GD: Acarbose rearrangement mechanism implied by the kinetic and structural analysis of human pancreatic alpha-amylase in complex with analogues and their elongated counterparts. Biochemistry 2005, 44(9):3347-3357.

47. Engh RA, Girod A, Kinzel V, Huber R, Bossemeyer D: Crystal structures of catalytic subunit of cAMP-dependent protein kinase in complex with isoquinolinesulfonyl protein kinase inhibitors $\mathrm{H7}, \mathrm{H8}$, and $\mathrm{H89}$ - Structural implications for selectivity. Journal of Biological Chemistry 1996, 27 I(42):26157-26I64. 
48. Fogle EJ, Liu WS, Woon ST, Keller JW, Toney MD: Role of $\mathbf{Q 5 2}$ in catalysis of decarboxylation and transamination in dialkylglycine decarboxylase. Biochemistry 2005, 44(50): $16392-16404$.

49. Ravelli RB, Raves ML, Ren Z, Bourgeois D, Roth M, Kroon J, Silman I, Sussman JL: Static Laue diffraction studies on acetylcholinesterase. Acta Crystallogr D Biol Crystallogr 1998, 54(Pt 6 Pt 2): $1359-1366$.

50. Sullivan JE, Holdgate GA, Campbell D, Timms D, Gerhardt S, Breed J, Breeze AL, Bermingham A, Pauptit RA, Norman RA, Embrey KJ, Read J, VanScyoc WS, Ward WH: Prevention of MKK6-dependent activation by binding to p38 alpha MAP kinase. Biochemistry 2005, 44(50): 16475-16490.

5I. Gloster TM, Roberts S, Perugino G, Rossi M, Moracci M, Panday N, Terinek M, Vasella A, Davies GJ: Structural, kinetic, and thermodynamic analysis of glucoimidazole-derived glycosidase inhibitors. Biochemistry 2006, 45(39): | | 879-1 I 884.

52. Guddat LW, Shan L, Anchin JM, Linthicum DS, Edmundson AB: Local and transmitted conformational changes on complexation of an anti-sweetener Fab. J Mol Biol 1994, 236(I):247-274.

53. Poulos TL, Finzel BC, Howard AJ: High-resolution crystal structure of cytochrome P450cam. J Mol Biol 1987, 195(3):687-700.

54. Biswal BK, Wang MT, Cherney MM, Chan L, Yannopoulos CG, Bilimoria $D$, Bedard J, James MNG: Non-nucleoside inhibitors binding to hepatitis C virus NS5B polymerase reveal a novel mechanism of inhibition. J Mol Biol 2006, 36 I(I):33-45.

55. Yang WJ, Lu WL, Lu YF, Zhong M, Sun J, Thomas AE, Wilkinson JM, Fucini RV, Lam M, Randal M, Shi XP, Jacobs JW, McDowell RS, Gordon EM, Ballinger MD: Aminoethylenes: A tetrahedral intermediate isostere yielding potent inhibitors of the aspartyl protease BACE-I. Journal of Medicinal Chemistry 2006, 49(3):839-842.

56. Ghosh AK, Kumaragurubaran N, Hong L, Lei H, Hussain KA, Liu CF, Devasamudram T, Weerasena V, Turner R, Koelsch G, Bilcer G, Tang J: Design, synthesis and $\mathbf{X}$-ray structure of protein-ligand complexes: Important insight into selectivity of memapsin 2 (beta-secretase) inhibitors. Journal of the American Chemical Society 2006, I 28(16):5310-53|I.

57. Vyas NK, Vyas MN, Quiocho FA: Sugar and signal-transducer binding sites of the Escherichia coli galactose chemoreceptor protein. Science 1988, 242(4883): 1290-1295.

58. Sacchettini JC, Gordon JI, Banaszak Lj: Crystal structure of rat intestinal fatty-acid-binding protein. Refinement and analysis of the Escherichia coli-derived protein with bound palmitate. J Mol Biol 1989, 208(2):327-339.

59. Proisy N, Sharp SY, Boxall K, Connelly S, Roe SM, Prodromou C, Slawin AMZ, Pearl LH, Workman P, Moody CJ: Inhibition of Hsp90 with synthesis macrolactones: Synthesis and structural and biological evaluation of ring and conformational analogs of radicicol. Chemistry \& Biology 2006, I3(I I): | 203-12 I5.

60. Healy-Fried ML, Funke T, Priestman MA, Han H, Schonbrunn E: Structural basis of glyphosate tolerance resulting from mutations of Pro( $(\mathrm{O} O \mathrm{I})$ in Escherichia coli 5-enolpyruvylshikimate-3-phosphate synthase. Journal of Biological Chemistry 2007, 282(45):32949-32955.

61. Varghese JN, Smith PW, Sollis SL, Blick TJ, Sahasrabudhe A, McKimmBreschkin JL, Colman PM: Drug design against a shifting target: a structural basis for resistance to inhibitors in a variant of influenza virus neuraminidase. Structure 1998, 6(6):735-746.

62. Badger J, Krishnaswamy S, Kremer MJ, Oliveira MA, Rossmann MG, Heinz BA, Rueckert RR, Dutko FJ, McKinlay MA: Three-dimensional structures of drug-resistant mutants of human rhinovirus I4. J Mol Biol 1989, 207(I):163-174.

63. Whitlow M, Howard AJ, Finzel BC, Poulos TL, Winborne E, Gilliland GL: A metal-mediated hydride shift mechanism for xylose isomerase based on the I.6 A Streptomyces rubiginosus structures with xylitol and D-xylose. Proteins 1991, 9(3): $153-173$.

64. Lolis E, Alber T, Davenport RC, Rose D, Hartman FC, Petsko GA: Structure of yeast triosephosphate isomerase at I.9-A resolution. Biochemistry 1990, 29(28):6609-66।8.

65. Marquart M, Walter J, Deisenhofer J, Bode W, Huber R: The geometry of the reactive site and of the peptide groups in trypsin, trypsinogen and its complexes with inhibitors. Acta Crystallographica Section B 1983, 39(4):480-490.
66. Weis WI, Brunger AT, Skehel J], Wiley DC: Refinement of the influenza virus hemagglutinin by simulated annealing. $J \mathrm{Mol}$ Biol 1990, 21 2(4):737-761.

67. Vermersch PS, Lemon DD, Tesmer JJ, Quiocho FA: Sugar-binding and crystallographic studies of an arabinose-binding protein mutant (Met 108Leu) that exhibits enhanced affinity and altered specificity. Biochemistry I99I, 30(28):686I-6866.

68. Morris GM, Goodsell DS, Halliday RS, Huey R, Hart WE, Belew RK, Olson AJ: Automated docking using a Lamarckian genetic algorithm and an empirical binding free energy function. J Comput Chem 1998, 19(14):1639-1662.

69. Wang RX, Fang XL, Lu YP, Yang CY, Wang SM: The PDBbind database: Methodologies and updates. Journal of Medicinal Chemistry 2005, 48( I 2):4||| -4|| 9 .

70. Stewart J]: Application of the PM6 method to modeling proteins. J Mol Model 2008.

7I. Abagyan R, Totrov M, Kuznetsov D: Icm - a New Method for Protein Modeling and Design - Applications to Docking and Structure Prediction from the Distorted Native Conformation. J Comput Chem I994, I 5(5):488-506.

72. Rarey M, Kramer B, Lengauer T, Klebe G: A fast flexible docking method using an incremental construction algorithm. J Mol Biol I996, 26 I(3):470-489.

73. Jones G, Willett P, Glen RC, Leach AR, Taylor R: Development and validation of a genetic algorithm for flexible docking. J Mol Biol 1997, 267(3):727-748.

74. Hetenyi C, Paragi G, Maran U, Timar Z, Karelson M, Penke B: Combination of a modified scoring function with two-dimensional descriptors for calculation of binding affinities of bulky, flexible ligands to proteins. Journal of the American Chemical Society 2006, I 28(4): | $233-1239$.

75. Reulecke I, Lange G, Albrecht J, Klein R, Rarey M: Towards an integrated description of hydrogen bonding and dehydration: decreasing false positives in virtual screening with the HYDE scoring function. Chem Med Chem 2008, 3(6):885-897.

76. Wang J, Kollman PA, Kuntz ID: Flexible ligand docking: A multistep strategy approach. Proteins-Structure Function and Genetics 1999, 36(I): I-19.

77. Storer JW, Giesen DJ, Cramer CJ, Truhlar DG: Class-Iv Charge Models - a New Semiempirical Approach in QuantumChemistry. Journal of Computer-Aided Molecular Design 1995, 9(I):87-I I0.

\footnotetext{
Publish with ChemistryCentral and every scientist can read your work free of charge

"Open access provides opportunities to our colleagues in other parts of the globe, by allowing anyone to view the content free of charge."

W. Jeffery Hurst, The Hershey Company.

- available free of charge to the entire scientific community

- peer reviewed and published immediately upon acceptance

- cited in PubMed and archived on PubMed Central

- yours - you keep the copyright

Submit your manuscript here

http://www.chemistrycentral.com/manuscript/
} 